05,12

\title{
Бистабильное и многодоменное состояния ферромагнитных микропроводов $\alpha$-Fe/(PrDy)(FeCo)B
}

\author{
() О.В. Коплак ${ }^{1}$, В.Л. Сидоров ${ }^{2}$, Е.И. Куницына ${ }^{1}$, Р.А. Валеев ${ }^{3}$, Д.В. Королев ${ }^{3}$, \\ В.П. Пискорский ${ }^{3}$, Р.Б. Моргунов ${ }^{1,3,9}$ \\ ${ }^{1}$ Институт проблем химической фризики РАН, \\ Черноголовка, Россия \\ ${ }^{2}$ Московский государственный университет им. М.В. Ломоносова, \\ Москва, Россия \\ ${ }^{3}$ Всероссийский институт авиационных материалов, \\ Москва, Россия \\ ฯ E-mail: morgunov2005@yandex.ru
}

Поступила в Редакцию 19 июня 2019 г.

В окончательной редакции 19 июня 2019 г.

Принята к публикации 24 июня 2019 г.

\begin{abstract}
Микропровода $\alpha$ - $\mathrm{Fe}(50$ at.\%)(PrDy)(FeCo)B(48 at.\%) получены экстракцией висящей капли расплава $(\mathrm{PrDy})(\mathrm{FeCo}) \mathrm{B}$ в электронном пучке. Показано, что одиночный микропровод диаметром $50 \mu \mathrm{m}$ и длиной $0.8-6 \mathrm{~mm}$ с содержанием аморфной фазы $(\mathrm{PrDy})(\mathrm{FeCo}) \mathrm{B} \sim 48 \%$ и поликристаллической фазой $\alpha$-Fe $\sim 52 \%$, обладает прямоугольной узкой петлей магнитного гистерезиса и, соответственно, бистабильным состоянием с полем переключения $\sim 100$ Ое. Укорочение провода до $\sim 0.6 \mathrm{~mm}$ приводит к резкому отклонению от прямоугольности петли, уменьшению наклона зависимости намагниченности от поля и коэрцитивной силы до 20 Oе. В приповерхностных слоях, состоящих из аморфной фазы $(\mathrm{PrDy})(\mathrm{FeCo}) \mathrm{B}$, наблюдаются ориентированные области обратной намагниченности. Обсуждается роль магнитного дипольного взаимодействия в формировании петли магнитного гистерезиса хаотичных ансамблей микропроводов различных составов.
\end{abstract}

Ключевые слова: магнитный микропровод, замыкающие домены, магнитострикция.

DOI: 10.21883/FTT.2019.11.48412.524

\section{1. Введение}

Ферромагнитные микропроволоки являются квазиодномерными объектами, в которых специфика движения доменных стенок определяется конкуренцией поля размагничивания и внутрикристаллической анизотропией. Это позволяет обнаруживать новые физические явления, такие как распространение доменных стенок со сверхзвуковой скоростью [1], создание магнитохиральных доменов разного знака [2], переходы между детерминированными и стохастическими режимами перемагничивания в нелинейной системе микропроводов [3] и многие другие эффекты, важные для физики магнетизма. Кроме того, магнитные микропроволоки занимают значительную нишу в производстве миниатюрных датчиков различного типа. В [4] описаны многочисленные практические применения микропроводов в качестве сенсоров магнитного поля, электрического тока, механических напряжений, температуры, магнитоимпедансных сенсоров, электронного компаса, магнитных микроманипуляторов (ножниц и пинцетов), магнитных шифровальных устройств, детекторов биологических объектов, приборов неразрушающего контроля трещин, композитов для поглощения микроволн.

Функциональные требования к магнитным микропроводам заключаются в том, чтобы [5]: 1) их диаметр находился в диапазоне $10-50 \mu \mathrm{m}$, делая их совместимыми с микроскопическими объектами, 2) поле переключения намагниченности должно быть низким 10-100 Ое, и 3) имела место магнитная бистабильность, которая заключается в резком переключении намагниченности микропровода при низком значении приложенного магнитного поля. Последнее требование соответствует узкой петле магнитного гистерезиса с формой, близкой к прямоугольной [5]. Магнитная бистабильность становится возможной благодаря монодоменному ядру в центральной части микропровода, намагниченность которого скачком переключается в пороговом магнитном поле. Поле рассеяния локализовано на концах провода, что приводит к образованию замыкающих доменов только на его концах. Если длина микропровода $L$ оказывается выше удвоенной длины области замыкающих доменов $2 L_{c d}$, скачкообразное перемагничивание монодоменного ядра (магнитная бистабильность) становится возможным. Например, в микропроводах $\mathrm{FeSiB}, \mathrm{CoSiB}$, $\mathrm{NiCoB}$ диаметром около $10 \mu \mathrm{m}$, покрытых стеклом, минимальная критическая длина микропровода составляет около $2 \mathrm{~mm}$, что вполне подходит для применения в микросенсорах [6]. Прямоугольная форма петли гистерезиса связана с очень высокой скоростью распространения доменной стенки. Было продемонстрировано, что процесс перемагничивания магнитного микропровода начинается с конца образца в результате депиннинга доменных стенок и последующего распространения до- 
менных границ из области замыкающих доменов [7,8]. Укорочение микропровода приводит к потере бистабильности и появлению многодоменных состояний. Еще одним условием „прямоугольности“ петли магнитного гистерезиса является положительная константа магнитострикции [9].

Значительная часть публикаций о ферромагнитных проводах связана с материалами на основе переходных металлов (в основном $\mathrm{Fe}$ ). С точки зрения упомянутых выше условий этот выбор представляется естественным в силу низкой коэрцитивной силы объемных образцов железа. Поэтому изготовление микропроводов из магнитожестких сплавов редкоземельных магнитов семейства RE-TM-B (RE - редкоземельный металл, TM переходный металл) на первый взгляд представляется нерациональным. В качестве примера можно указать микропровода $\mathrm{NdFeB}$ с довольно высокой положительной константой магнитострикции $+52 p p m$, в которых, однако не наблюдается магнитная бистабильность [10]. Методы получения микропроводов часто связаны с высокой скоростью охлаждения расплава, в результате которого происходит расслоение фазы RE-TM-B на аморфную редкоземельную составляющую с низкой коэрцитивной силой и микрокристаллическую часть, состоящую из переходных металлов [11]. Поэтому попытки приготовления магнитомягких микропроводов из расплавов RE-TM-B вполне могут приводить к получению микропроводов с необходимыми функциональными свойствами.

Целью работы было создание ферромагнитных бистабильных микропроводов из быстро охлаждаемого расплава $(\mathrm{DyPr})(\mathrm{FeCo}) \mathrm{B}$ методом экстракции висящей капли, а также анализ фазового расслоения в формировании их бистабильности и сравнение свойств одиночных микропроводов с магнитными свойствами их хаотичных ансамблей.

\section{2. Методика экспериментов и приготовление образцов}

Микропровода получали методом экстракции висящей капли расплава (ЭВКР) из сплава $(\mathrm{PrDy})(\mathrm{FeCo}) \mathrm{B}$, при повышенной скорости охлаждения. Этот метод был предложен в [12] и адаптирован для редкоземельных магнитов в [13] с использованием нагрева капли электронным пучком. Химический и фазовый состав микропроводов приведен в табл. 1. Типичный радиус микропроводов составлял 25-50 $\mu \mathrm{m}$, а максимальная длина до $\sim 10 \mathrm{~mm}$ (рис. 1,a). Морфологию поверхности и распределение градиента магнитных сил на поверхности образцов исследовали методом атомно-силовой (ACM) и магнитной силовой микроскопии (МСМ) соответственно. Двухпроходный метод МСМ позволяет минимизировать влияние рельефа на картину распределения магнитных сил [14]. Изображения доменной структуры в исследуемых образцах были получены с помощью атомного силового
Таблица 1. Фазовый и химический составы поверхностей микропроводов, полученные микрорентгеноспектральным анализом

\begin{tabular}{c|c|c}
\hline $\begin{array}{c}\text { Химический } \\
\text { состав, at.\% }\end{array}$ & Размеры & $\begin{array}{c}\text { Фазовый } \\
\text { состав, vol.\% }\end{array}$ \\
\hline $\operatorname{Pr}_{7.4} \mathrm{Dy}_{6.3} \mathrm{Fe}_{50.9} \mathrm{Co}_{28.6} \mathrm{~B}_{6.8}$ & $0.1 \times 2000 \mu \mathrm{m}^{2}$ & $\begin{array}{c}\text { Фаза } \alpha \text {-Fe }(52 \%) \\
\text { Аморфная фаза } \\
(\mathrm{PrDy})(\mathrm{FeCo}) \mathrm{B}(48 \%)\end{array}$
\end{tabular}

микроскопа Aura Integra (NT MDT) в отсутствие магнитного поля. Измеряемые значения магнитной силы, пропорциональные градиенту магнитного поля вблизи поверхности образца, были также пропорциональны частотному сдвигу вибрирующего кантилевера на основе $\mathrm{CoCr}$ с коэрцитивной силой $400 \mathrm{Oe}$. Силовая константа и резонансная частота кантилевера были равны $5 \mathrm{~N} / \mathrm{m}$ и $69 \mathrm{kHz}$ соответственно. Расстояние кантилевера от поверхности составляло $70 \mathrm{~nm}$ и было одинаковым во всех опытах в режиме „tapping-lift“. Локальный элементный состав (EDX анализ) и изображения поверхности микропроводов получены на растровом электронном микроскопе SUPRA 25 (Zeiss). Микрорентгеноспектральный анализ проведен на установке „Суперпроб-733“ (JEOL) с использованием энергодисперсионного микроанализатора „Inca Energy“. Локальность анализа составляла $1 \mu \mathrm{m}^{2}$, а глубина исследуемой области - $1 \mu \mathrm{m}$. Контраст изображения структуры в отраженных электронах определяется средним атомным номером фазы: чем выше атомный номер, тем светлее данный участок. Структурные свойства образцов были исследованы на дифрактометре ДРОН-УМ2, $\theta-2 \theta$-сканирование в диапазоне $10-80 \mathrm{deg}, \mathrm{Cu} K \alpha$-излучение. Шаг сканирования - 0.02 градуса. Магнитные гистерезисы получены на СКВИД-магнетометре MPMS XL Quantum Design при $300 \mathrm{~K}$.

\section{3. Результаты}

На рис. 1, $a$ приведено изображение микропровода, полученное в сканирующем электронном микроскопе. Изображение АСМ, свидетельствует об относительно гладкой поверхности микропровода с низким параметром шероховатости $\sim 1.2 \mathrm{~nm}$ (рис. $1, b$ ). Распределение намагниченности в центре микропровода содержало области обратной намагниченности (темные пятна на рис. 1,c, ориентированные вдоль оси микропровода). Различие между АCM (рис. $1, b)$ и МСМ-изображениями (рис. $1, c)$ одного и того же участка, говорит о том, что магнитное изображение вызвано не шероховатостью образца, а отражает распределение намагниченности элементов образца.

Результаты рентгенофазового анализа (табл. 1) и энергодисперсионного анализа (EDX) (табл. 2) показали 

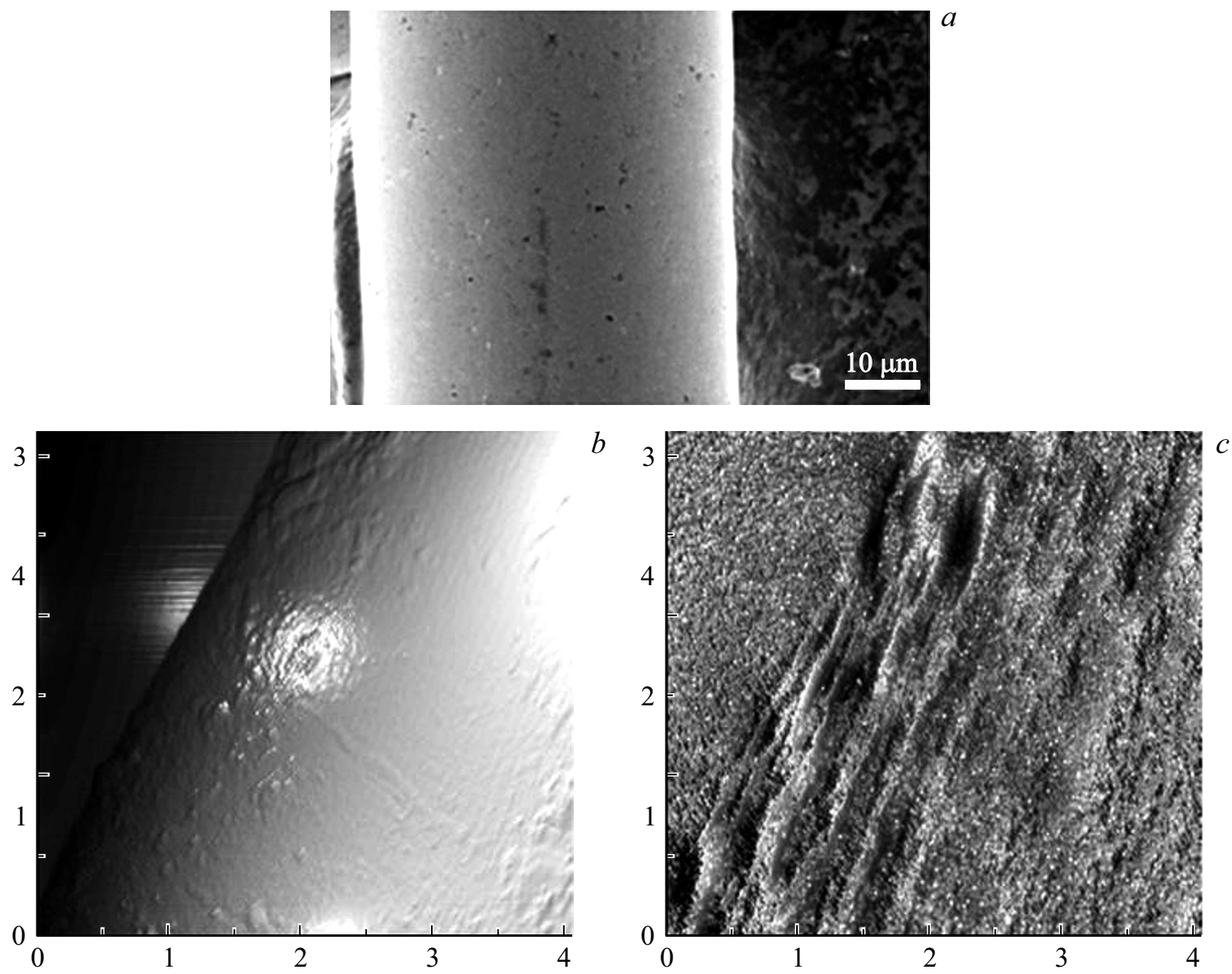

Рис. 1. Изображение микропровода, полученное: сканирующим электронным микроскопом $(a)$ с масштабом $200 \times 280 \mu \mathrm{m}$, и атомным силовым микроскопом в режиме АCM $(b)$ и $\mathrm{MCM}(c)$ с масштабом $7 \times 7 \mu \mathrm{m}$.

весьма близкие химические составы относительно элементов Pr, Dy, Co, Fe. Отметим, что рентгенофазовый анализ характеризует суммарные вклады поверхностных и объемных слоев, в то время, как результаты EDX анализа могут быть отнесены лишь к тонким поверхностным слоям $\sim 20 \mathrm{~nm}$. Кроме того, EDX анализ в используемом микроскопе не позволял регистрировать бор, и поэтому концентрации в табл. 2 были получены с учетом данных для бора в табл. 1. Атомные доли элементов $\mathrm{Pr}$, Dy, Co, Fe, полученные методом EDX приведены на рис. 2, а вместе с участком, выбранным для анализа (вставка на рис. 2, $b$ ). Спектр рентгеновской дифракции одиночного микропровода (рис. 2,b) содержал гало, возникшее из-за наличия аморфной фазы, а также линии $1-3$, отвечающие характерному спектру $\alpha$-Fe. Отметим, что значительное уширение линий спектра свидетельствует о значительной доле аморфной фазы в микропроволоках.

Исследование торца микропровода с помощью сканирующего электронного микроскопа (рис. 3), позволило установить зависимость химического состава от удаления от поверхности к центру микропровода (табл. 2). Видно, что химический состав меняется незначительно, а причиной этих изменений является загрязнение поверхности атомами $\mathrm{Al}$ и $\mathrm{As}$ при получении микропроводов.

Таблица 2. Содержание элементов (at.\%) за вычетом 6.8\% бора в приповерхностном слое микропровода в точках $1-4$ (рис. 6), в которых был выполнен EDX анализ

\begin{tabular}{c|c|c|c|c|c|c}
\hline Номер точки & Al at.\% & Fe at.\% & Co at.\% & As at.\% & Pr at.\% & Dy at.\% \\
\hline 1 & 4.75 & 48.45 & 27.31 & 2.38 & 6.46 & 4.05 \\
2 & 0 & 51.22 & 29.03 & 0.00 & 6.67 & 6.28 \\
3 & 0 & 51.79 & 29.32 & 0.00 & 6.35 & 5.74 \\
4 & 0 & 52.60 & 30.01 & 0.00 & 6.39 & 4.56
\end{tabular}



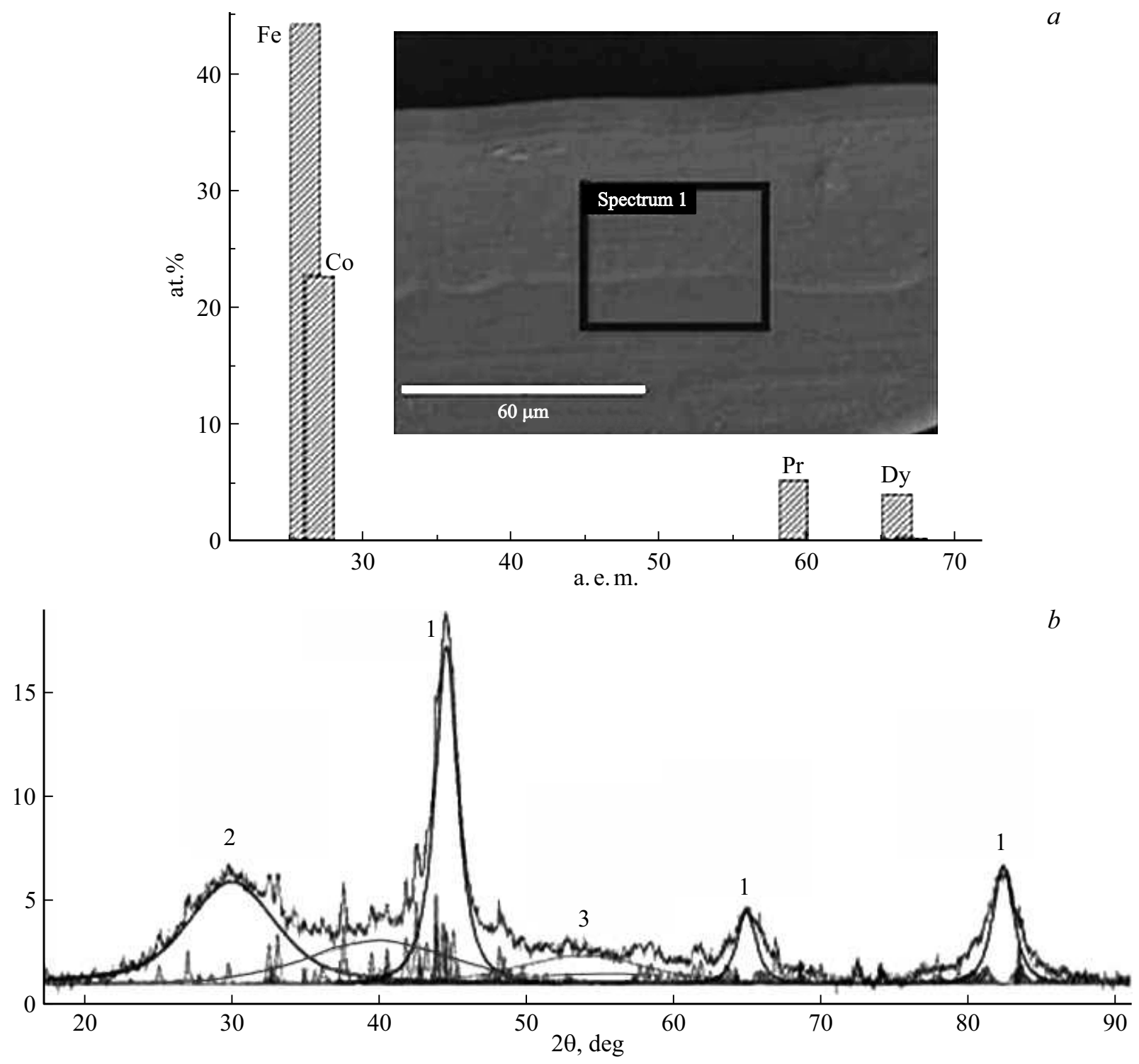

Pис. 2. (а) Относительные доли Dy, Pr, Co, Fe в микропроводе, рассчитанные из спектра EDX (на врезке показан участок микропровода, на котором были получены спектры), $(b)$ - спектр рентгеновской дифракции микропровода, с линиями фаз $\alpha$-Fe $(1),(\mathrm{PrDy})_{2}(\mathrm{FeCo})_{14} \mathrm{~B}(2)$ и гало аморфной фазы, оцененное с помощью двух Гауссианов (3).

Петля магнитного гистерезиса одиночного микропровода с коэрцитивной силой 105 Ое была близка к прямоугольной форме при ориентации внешнего магнитного поля вдоль оси микропровода (рис. $4, a$, кривая 1 ). Показатель „прямоугольности“, оцененный по намагниченности насыщения $M_{S}$ и остаточной намагниченности $M_{R}$ составлял $Q=1-M_{R} / M_{S}=0.93$. В перпендикулярной ориентации внешнего магнитного поля по отношению к оси микропровода наклон петли гистерезиса был выше, чем в параллельной ориентации (рис. 4, $a$, кривая 2), что говорит о том, что главная ось намагниченности лежит вдоль оси микропровода. Хаотичный ансамбль микропроводов разной длины $0.5-20 \mathrm{~mm}$ имел сложную форму петли гистерезиса с коэрцитивной силой 983 Ое (рис. $4, b$ ).

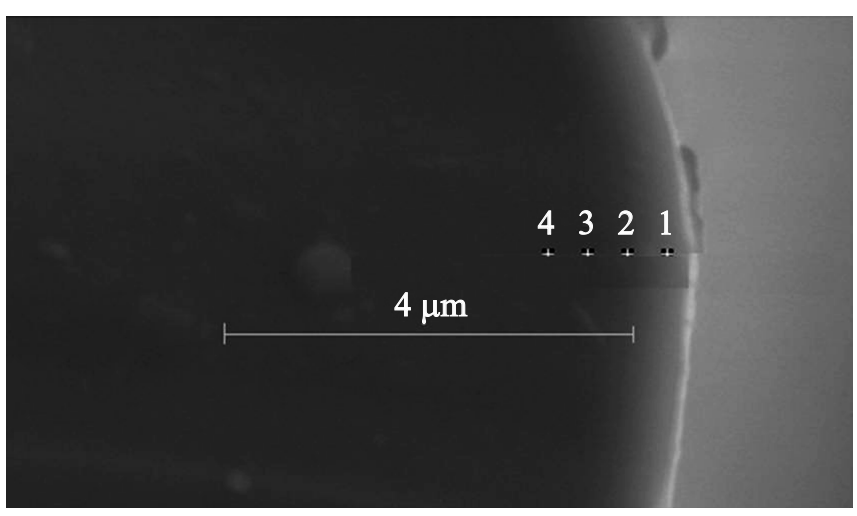

Рис. 3. Изображение торца микропровода, полученное с помощью сканирующего электронного микроскопа и точки, в которых определялся химический состав методом EDX для табл. 2. 

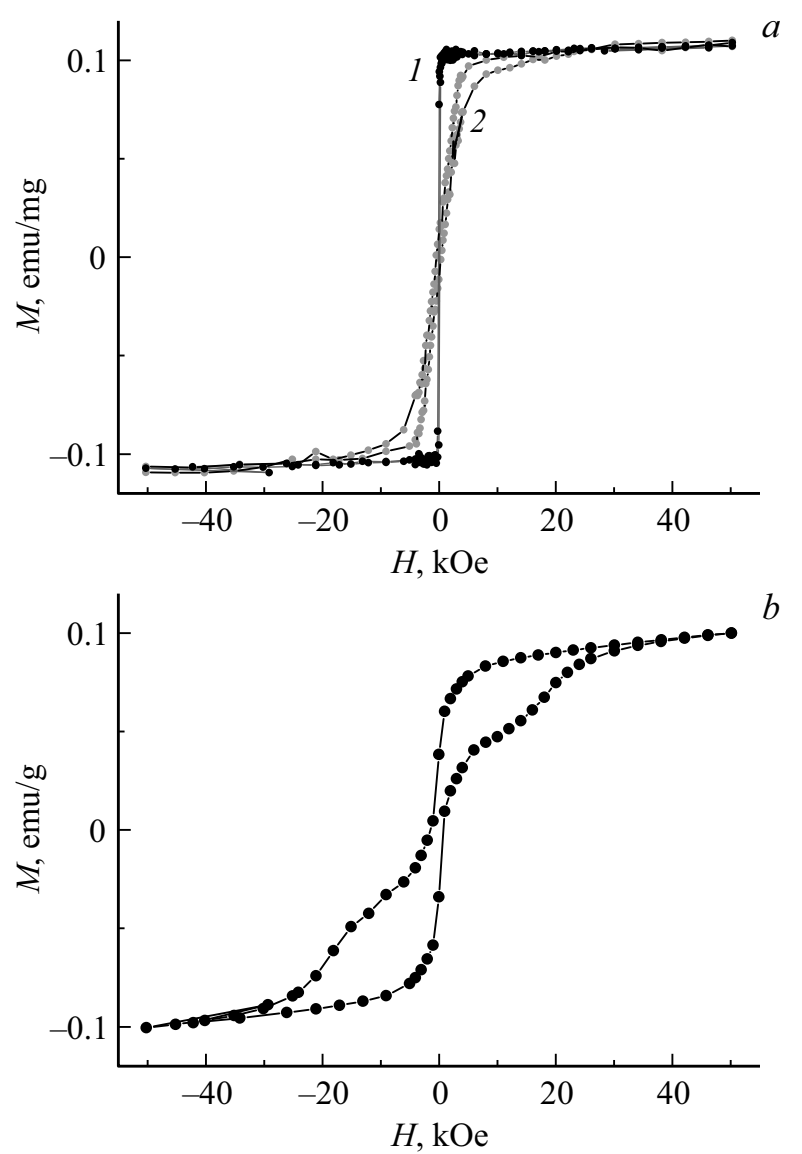

Рис. 4. Петли магнитного гистерезиса при $T=300 \mathrm{~K}$ : $(a)$ одного микропровода, ориентированного вдоль магнитного поля $(1)$ и перпендикулярно полю $(2) ;(b)-$ множества микропроводов первого типа $\sim 100$, ориентированных случайным образом.

Для определения критической длины микропровода $2 L_{c d}$ его постепенно укорачивали, каждый раз измеряя петли магнитного гистерезиса для одного и того же микропровода разной длины. Избранные фрагменты этой серии измерений показаны на рис. 5. Видно, что укорочение микропровода приводило к уменьшению коэрцитивной силы от 100 до 20 Ое и наклона петли гистерезиса, снижая показатель „прямоугольности“ $Q$ от 0.93 до 0.18 (рис. 6). Кроме того, петли гистерезиса становились ассиметричными (рис. 5,c), что указывает на возникновение эффекта обменного смещения на интерфейсе между фазой $\alpha$-Fe и аморфной фазой $(\mathrm{PrDy})(\mathrm{FeCo}) \mathrm{B}$. Коэрцитивная сила микропровода скачком уменьшалась в 5 раз при достижении длины $0.6 \mathrm{~mm}$ (рис. 6), которую можно воспринимать, как экспериментально определенную величину удвоенного размера области замыкающих доменов $2 L_{c d}$.

\section{4. Обсуждение}

Источником магнитной анизотропии помимо магнитокристаллической анизотропии является анизотропия формы. В случае микропроводов анизотропия формы может быть значительной и приводит к существованию критической длины микропровода, разделяющего многодоменное состояние при „малых“ длинах и однодоменное состояние ядра с небольшим вкладом замыкающих доменов на концах „длинного“ микропровода. Критическая длина $L_{c}$ для наблюдения магнито-бистабильного состояния связана с существованием „замыкающих“ доменов на концах проводов и с проникновением замыкающих доменов размером $L_{c d}$ внутрь микропровода как $L_{c} \approx 2 L_{c d}=\left(1-M_{R} / M_{S}\right) \cdot L$. Следовательно, для данного образца при фиксированном диаметре уменьшение его длины приведет к увеличению коэффициента размагничивания. Другими словами, уменьшение диаметра для данной длины должно привести к уменьшению проникновения в область замыкания и критической длины $L_{c}$ бистабильности [5-8]. В частности, для микропровода длиной $L=2 \mathrm{~mm}$ получим $L_{c}=140 \mu \mathrm{m}\left(M_{r} / M_{s}=0.93\right.$, рис. $4, a)$. Это означает, что при длине микропровода $L>0.14 \mathrm{~mm}$ факторы размагничивания не влияют на форму петли гистерезиса.

Прямоугольная петля гистерезиса становится возможной благодаря существованию однодоменного внутреннего ядра намагниченности в микропроволоке. Размер этого ядра $R_{c}$ в микропроводах $(\mathrm{PrDy})(\mathrm{FeCo}) \mathrm{B}$ определяется отношением остаточной намагниченности $M_{R}=0.0093 \mathrm{emu} / \mathrm{g}$ к намагниченности насыщения $M_{S}=0.010 \mathrm{emu} / \mathrm{g}$ и радиусом микропровода $R_{w}=35 \mu \mathrm{m}: R_{c}=\left(M_{R} / M_{S}\right)^{1 / 2} R_{w} \approx 0.75 R_{w}=26 \mu \mathrm{m}$. Уменьшенные размеры магнитного однодоменного ядра по сравнению с радиусом микропровода $R_{c} \approx 0.75 R_{w}$ означают, что приповерхностные слои могут иметь существенно иной химический состав. Это подтверждается тем, что EDX анализ не показывает линий $\alpha$-Fe в приповерхностных слоях микропроводов (рис. 2,a), а рентгеноструктурный анализ, использующий излучение, проникающее в объем проволок, указывает на сосуществование аморфной фазы $(\mathrm{PrDy})(\mathrm{FeCo}) \mathrm{B}$ и фазы $\alpha$-Fe (рис. $2, b)$. Более того, отношение объема ядра к объему проволоки $\left(R_{w} / R_{c}\right)^{2} \sim 0.5$ близко к данным об атомной доле $\alpha$-Fe и аморфной фазы $(\mathrm{PrDy})(\mathrm{FeCo}) \mathrm{B} \sim 0.5$ в микропроводе (табл. 1). Эти данные позволяют заключить, что ядро микропровода состоит из магнитомягкой фазы $\alpha$-Fe, а поверхностные слои - из аморфной фазы $(\mathrm{PrDy})(\mathrm{FeCo}) \mathrm{B}$. Такой вывод представляется хорошо согласующимся с небольшой величиной поля переключения, более характерной для микропроводов на основе железа, чем для редкоземельных магнитов. Из рис. 3 следует, что сама аморфная фаза практически однородна, будучи лишь немного загрязненной Al и As в приповерхностных слоях (табл. 2). Вытянутые темные области вдоль оси микропровода на изображении магнитного контраста (рис. $1, c)$, соответствуют областям обратной намагниченности в середине микропровода, которые могут быть изображением полей рассеяния отдельных микрокристаллитов в аморфной фазе $(\mathrm{PrDy})(\mathrm{FeCo}) \mathrm{B}$, текстурированных при вытягивании микропровода. 

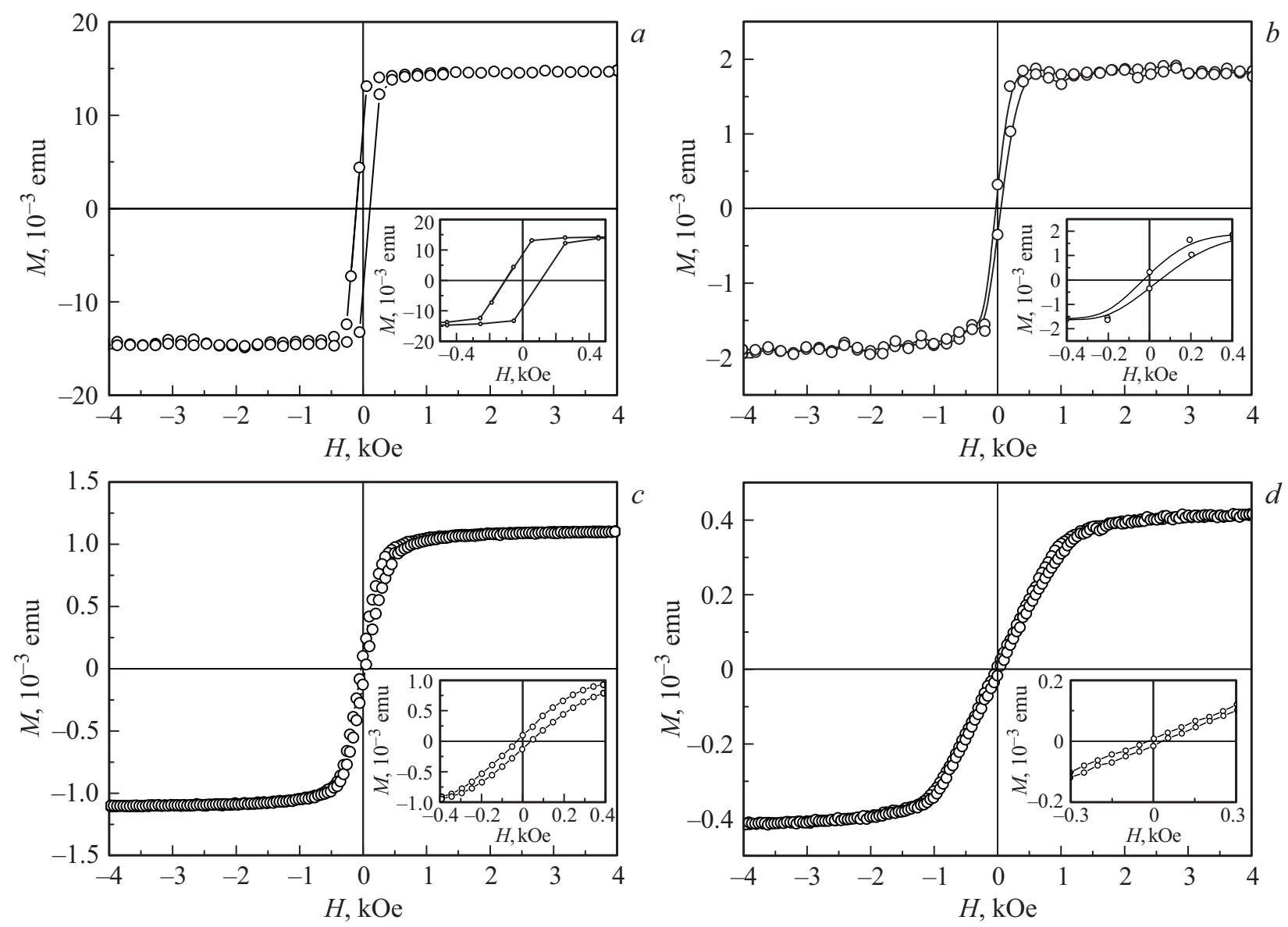

Рис. 5. Петли магнитного гистерезиса одного и того же микропровода, последовательно укорачиваемого от $0.8 \mathrm{~mm}(a)$ до $0.6 \mathrm{~mm}(b), 0.3 \mathrm{~mm}(c), 0.2 \mathrm{~mm}(d)$.

Поле размагничивания отдельного микропровода можно оценить согласно формуле [1-2]:

$$
\begin{aligned}
H_{d}=N M_{S} & =4 \pi M_{S}\left([\ln (2 L / D)-1](D / L)^{2}\right) \\
& =0.78 M_{S} \sim 400 \mathrm{Oe} .
\end{aligned}
$$

При используемых размерах $L=2 \mathrm{~mm}, D=50 \mu \mathrm{m}$ и намагниченности насыщения $M_{S}=839 \mathrm{emu} / \mathrm{cm}^{3}$, величина поля размагничивания 654 Ое весьма существенна, как для отдельного микропровода с полем переключения $105 \mathrm{Oe}$ (рис. 4,a), так и для ансамбля хаотичных микропроводов с коэрцитивной силой $983 \mathrm{Oe}$ (рис. 4,b). Отметим, что согласно дипольной модели микропроволоки [15], продольная компонента ее поля на конце $H_{z}$, создаваемого магнитным полюсом конца, пропорциональна намагниченности насыщения микропроволоки $M_{S}$ :

$$
H_{z}=K M_{S} ; \quad \text { где } \quad K=V / 4 \pi \mu_{0} r^{3}
$$

где $V$ - объем магнитного ядра микропроволоки, $r$ - расстояние от ее конца. Полагая, что наименьшее удаление конца одного микропровода от поверхности другого микропровода по порядку вели-

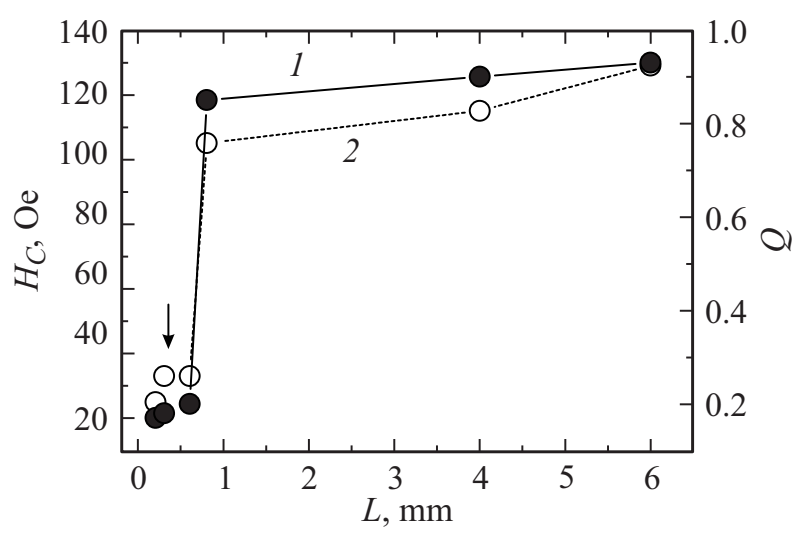

Рис. 6. Зависимость поля переключения намагниченности $H_{c}(1)$ и параметра „прямоугольности“ $Q$ петли гистерезиca $(2)$ от длины микропровода $L$. Стрелкой показано расчетное значение критической длины провода.

чины равно удвоенной толщине внешнего аморфного слоя $r_{\min }=2\left(R_{w}-R_{c}\right)=24 \mu \mathrm{m}$, получим из (2) оценку сверху для поля, создаваемого концом одного микропровода и влияющего на другой микропровод: $H_{z}=M_{s} R_{c}^{2} L_{c d} / \mu_{0} r_{\min }^{3}=3.9 \mathrm{kOe.} \mathrm{Этого} \mathrm{поля} \mathrm{достаточно,}$ 
чтобы в ядре микропровода с полем переключения 105 Ое создать локальную доменную структуру, разрушающую однодоменное ядро. Поэтому можно указать два главных фактора, формирующих петлю гистерезиса хаотичного ансамбля микропроводов (рис. $4, b$ ):

1) разброс длин и ориентаций микропроводов, в диапазоне 0.5-20 mm, который дополняет вклад в петлю гистерезиса от микропроводов с „менее квадратными“ петлями;

2) пересечение микропроводов, в результате которого, локальное поле, создаваемое концами микропроводов в месте их контакта с другими микропроводами, нарушает их однодоменную структуру.

Отметим, что одна из технологий изготовления постоянных редкоземельных магнитов [16] включает в себя стадию приготовления аморфной фазы, которая затем кристаллизуется, образуя кристаллиты с заданным направлением главных осей намагниченности (магнитной текстурой). Именно эта стадия приводит к получению микропроводов, как побочного продукта, обладающего функциональными свойствами.

\section{5. Выводы}

1. Методом экстракции расплава капли в электронном пучке получены микропровода сплава (PrDy)(FeCo)B. Микропровода содержали 52 vol.\% поликристаллической фазы $\alpha$-Fe, образующей их ядра и поверхностный слой аморфного материала $(\mathrm{PrDy})(\mathrm{FeCo}) \mathrm{B}(\sim 48$ vol.\%).

2. В одиночном микропроводе диаметром $50 \mu \mathrm{m}$ и длиной $20 \mathrm{~mm}$ наблюдается квадратная петля гистерезиса с полем переключения намагниченности 105 Ое, что свидетельствует о наличии магнитного бистабильного состояния и высокой скорости движения доменных стенок при перемагничивании микропровода. Фазовый анализ и величина поля переключения соответствуют наличию однодоменного ядра фазы $\alpha$-Fe, покрытого аморфным материалом (PrDy)(FeCo)B. Такое распределение химических элементов и фаз в микропроводе возникло при высокой скорости охлаждения расплава (PrDy) $(\mathrm{FeCo}) \mathrm{B}$.

3. Укорочение микропровода до $0.6 \mathrm{~mm}$ приводит к резкому падению коэрцитивной силы и уменьшению параметра „прямоугольности“ петли магнитного гистерезиса в $\sim 5$ раз. „Прямоугольность“ петли гистерезиса теряется в ансамбле микропроводов из-за разброса в длинах и ориентациях микропроводов, а также магнитного дипольного взаимодействия между ними, разрушающего однодоменное состояние ядер. При длине провода, меньшей критической, бистабильное магнитное состояние, отвечающее однодоменной структуре, сменяется на многодоменное состояние.

4. Выявлены приповерхностные области обратной намагниченности, преимущественно ориентированные вдоль оси микропровода в его средней части, что наряду с наличием однодоменного ядра $\alpha$-Fe в сердцевине микропровода означает, что эти области формируются в аморфном слое $\mathrm{PrDyFeCoB}$ и, возможно, являются микрокристаллитами.

\section{Благодарности}

Авторы признательны Н.Н. Дремовой за помощь в получении данных на SEM.

\section{Финансирование работы}

Работа поддержана Президиумом Российской академии наук, грантом программы 18-030 II, тема 1 „Наноструктуры: физика, химия, биология, основы технологийс.

\section{Конфликт интересов}

Авторы заявляют, что у них нет конфликта интересов.

\section{Список литературы}

[1] R. Varga, A. Zhukov, V. Zhukova, J.M. Blanco, J. Gonzalez. Phys. Rev. B 76, 132406 (2007).

[2] Yu.P. Ivanov, R.P. del Real, O. Chubykalo-Fesenko, M. Vázquez. J. Appl. Phys. 115, 063909 (2014).

[3] J. Velazquez, M. Vazquez. Physica B 320, 230 (2002).

[4] H. Peng, F. Qin, M. Phan. Ferromagnetic microwire composites. From Sensors to Microwire applications. Springer, Series Engineering Materials and Processes. (2016). 245 p.

[5] A.M. Severino, C. Gómez-Polo, P. Marín, M. Vázquez. J. Magn. Magn. Mater. 103, 117 (1992).

[6] A. Zhukova, V. Zhukov, J.M. Blancoc, A.F. Cobeno, M. Vazquez, J. Gonzalez. J. Magn. Magn. Mater. 258, 151 (2003).

[7] S.A. Gudoshnikov, Yu.B. Grebenshchikov, B.Ya. Ljubimov, P.S. Palvanov, N.A. Usov, M. Ipatov, A. Zhukov, J. Gonzalez. Phys. Status Solidi A 206, 4, 613 (2009).

[8] J. Ye, R.P. del Real, G. Infante, M. Vazquez. J. Appl. Phys. 113, 043904 (2013).

[9] M. Vázquez, A. Jiménez, R.P. del Real. Woodhead Publishing Series in Electronic and Optical Materials. (2015). P. 379.

[10] P. Szary, I. Luciu, D. Duday, E.A. Périgo, T. Wirtz, P. Choquet, A. Michels. J. Appl. Phys. 117, 17D134 (2015).

[11] K. Yamamoto, T. Irie, M. Takeuchi. J. Jpn. Soc. Powder Powder Met. 63, 630 (2016).

[12] R.E. Maringer, C.E. Mobley. Vac. Sci. Technol. 11, 1067 (1974).

[13] М.М. Серов, Б.В. Борисов. Технология легких сплавов 3, 62 (2007).

[14] S.J. Lloyd, J.C. Loudon, P.A. Midley. J. Microscopy 207, 118 (2002).

[15] M. Knobel, L.C. Sampaio, E.H.C.P. Sinnecker, P. Vargas, D. Altbir. J. Magn. Magn. Mater. 249, 60 (2002).

[16] В.П. Пискорский, Д.В. Королев, Р.А. Валеев, Р.Б. Моргунов, Е.И. Куницына. Физика и инженерия постоянных магнитов / Под ред. Е.Н. Каблова. ВИАМ, М. (2018). $392 \mathrm{c}$.

Редактор Т.Н. Василевская 